\title{
BAYESIAN TIME-SERIES ANALYSES REVEAL A COMPLEX IMPACT OF CLIMATE CHANGE ON CLASSIC MAYA CONFLICT
}

PREPRINT

\author{
W. Christopher Carleton \\ Department of Archaeology \\ Simon Fraaer University \\ Burnaby, BC, Canada \\ william_carleton@sfu.ca
}

\author{
Dave Campbell \\ Department of Statistics and Actuarial Science \\ Simon Fraaer University \\ Burnaby, BC, Canada \\ dac5@sfu.ca
}

\author{
Mark Collard \\ Department of Archaeology \\ Simon Fraaer University \\ Burnaby, BC, Canada \\ mcollard@sfu.ca
}

February 19, 2019

\begin{abstract}
Researchers disagree about the impact of climate change on conflict among the Maya during the Classic period (ca. 250-900 CE). Some contend that increasing aridity exacerbated conflict, while others have found that increasing temperature ramped up conflict. Here, we report a study in which we sought to resolve this disagreement. We collated annually-resolved conflict and climate data, and then created a Bayesian time-series model for analysing count-based prehistoric and historic data. We carried out three analyses, one covering more or less the whole of the Classic Period (292-900 CE), one focused on the Early Classic (292-600 CE), and one that concentrated on the Late Classic (600-900 CE). Our analyses indicated that climate change likely did impact Classic Maya conflict levels, but our results differed from those of previous studies in two important ways. First, we found that the impact of climate change is only evident during the Late Classic. Second, we found that while increasing summer temperature exacerbated conflict, increasing aridity suppressed it. Thus, our study offers a new, more complex perspective on Classic Maya climate-conflict dynamics. It also has implications for our understanding of other aspects of Classic Maya history and for the debate about the likely impact of the current bout of climate change on conflict levels.
\end{abstract}

Keywords Climate Change $\cdot$ temperature $\cdot$ aridity $\cdot$ Classic Maya $\cdot$ conflict $\cdot$ human-environment interaction $\cdot$ Bayesian time-series analysis

\section{Introduction}

Concern is growing among policy-makers that the current bout of climate change could exacerbate conflict [1, 46, 21]. However, the scientific literature is far from clear about whether this is likely. Studies published recently have returned contradictory results. Some researchers have found that rising temperature is associated with increased conflict [e.g., [6], while others have failed to find any effect of increasing temperature on conflict levels [e.g., 5]. Still others have concluded that cooler rather than warmer temperatures lead to increased conflict [e.g., 44, 51]. The effect of rainfall on conflict is equally unclear. Some authors have found that rainfall variability increases conflict [e.g., 24], while others have concluded that it actually reduces conflict [e.g., 39, 43]. Even reviews of the literature covering dozens of individual studies have failed to clarify the situation [e.g., 24, 41, 17, 38]. Given the importance of the topic and the lack of consensus at present, there is clearly a need for additional research.

Here, we report a study that sought to shed light on the relationship between climate change and conflict in a well-known historical society - the Classic Maya. The Maya are indigenous people who occupy a region close to the middle of the isthmian portion of North America (Fig. 1). Scholars typically consider the Classic Period of Maya history to have begun in $250 \mathrm{CE}$ and to have ended around $900 \mathrm{CE}$ [42]. The period is often further subdivided into the Early Classic (250-600 CE) and Late Classic (600-900 CE) on the basis of changes in art and architectural styles that appear to be associated with a major cultural and political shift [32]. The Classic Maya are noteworthy for having constructed large 


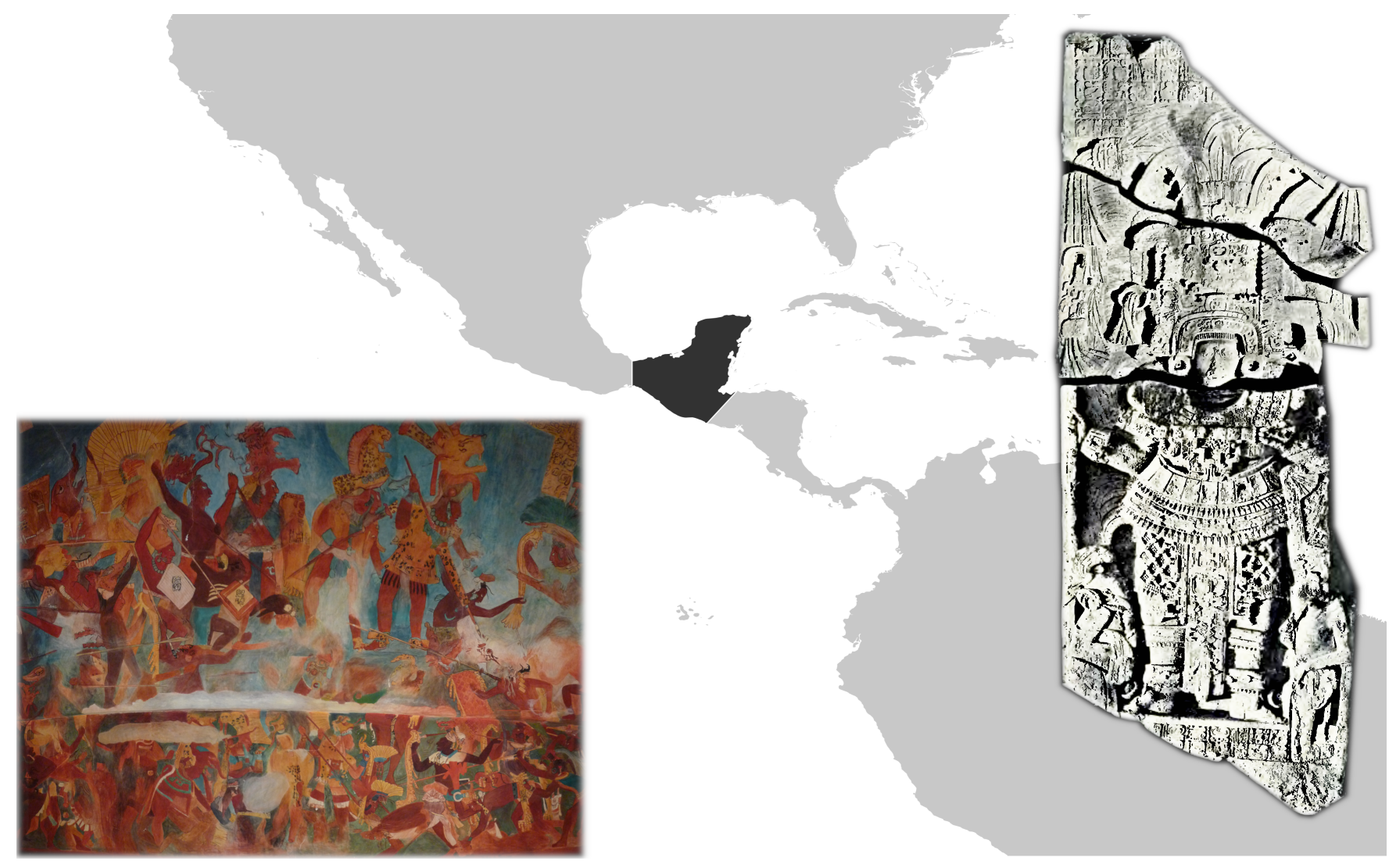

Figure 1: Map of the Maya region. The dark grey area roughly corresponds to the Classic Maya region. The bottomleft inset is a digitally enhanced photograph of one of the murals at Bonampak, a Classic Maya centre located in the Mexican state of Chiapas (modified from https://commons.wikimedia.org/wiki/File:Reproduction of_Bonampak_murals_(center)_2.JPG_-published under the Creative Commons Attribution-Share Alike 3.0 License). The mural depicts a violent conflict and was one of the first definitive pieces of evidence for such conflict among the Classic Maya [48]. The inset on the right is a photograph of Stela 8 from Piedras Negras in Northeastern Guatemala (modified from https://commons.wikimedia.org/wiki/File:Maler_Researches_in_the_ Central_Portion_of_the_Usumatsintla_Valley_Plate_XVII.png_-public domain image). The stela depicts Yo'nal Ahk II, ruler of Peidras Negras from 687-729 CE, presenting two captives [32, pg.147]. Stela such as this one are the primary source for Classic Maya historical data, including the conflict events at the centre of the present study.

cities featuring pyramids and other monumental buildings. They also developed one of the few writing systems in the Americas and a precise calendar [23, 37]. It is clear from translated inscriptions and surviving artwork that conflict was an important feature of Classic Maya life [4, 19, 26, 48]. Among the conflict events mentioned in the epigraphic record are captive-taking raids, attacks to demand tribute, and large coordinated offensives that appear timed to coincide with astronomical events and have therefore been dubbed "star wars" [48].

Recent studies have reached conflicting conclusions regarding the impact of climate change on Classic Maya conflict. Kennett et al. [28] compared the epigraphic record of Classic Maya conflict and an oxygen isotope $\left(\delta^{18} O\right)$ rainfall proxy from Yok Balum Cave, Belize, and found an association between drought and increased conflict. They argued that this association was caused by the negative impact of drought on the agricultural basis of Classic Maya society. Conflict levels increased, they suggested, because Maya polities fought over resources. Carleton et al. [7] arrived at a different conclusion. These authors used time-series analysis to compare the epigraphic record of Classic Maya conflict, the Yok Balum Cave $\delta^{18} O$ rainfall proxy, and sea-surface temperature reconstructions from the Cariaco Basin. They found no association between drought and conflict. Instead, their analyses indicated that conflict was influenced by summer temperatures. Carleton et al. [7] proposed that increasing numbers of growing season days above 30C led to declines in maize yields, and that these declines created crises of political legitimacy because of the symbolic 
association between rulership and maize. Crop failures were perceived as political failures and that undermined the elite's right to rule. In order to cope with this, Carleton et al. [7] suggested, members of the elite organized attacks on other polities, hoping that victory would restore that lost legitimacy.

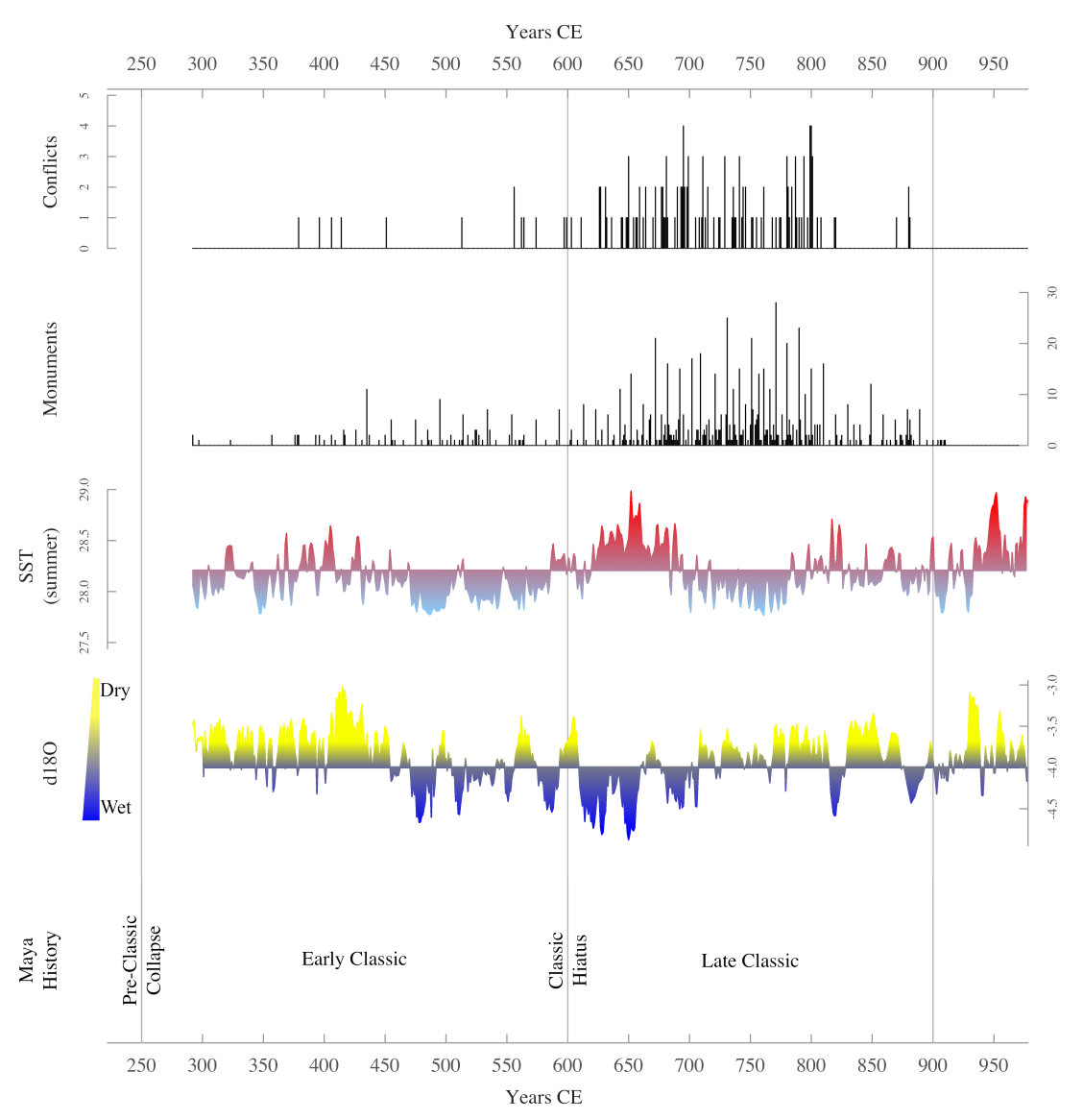

Figure 2: Time-series data and Classic Maya history.

Resolving this disagreement was the goal of our study. Low temporal resolution is one potential explanation for the failure of Kennett et al.'s [28] and Carleton et al.'s [7] analyses to yield congruent results. Both teams relied on data with a resolution of 25 years, which potentially obscured considerable interannual variation. As a result, it is possible that the studies did not capture real climate-conflict dynamics. With this in mind, we collated annually-resolved conflict and climate data (Fig. 2), and then created a Bayesian time-series model for analysing count-based prehistoric/historic data. We carried out three analyses, one covering more or less the whole of the Classic Period (292-900 CE), one focused on the Early Classic (292-600 CE), and one that concentrated on the Late Classic (600-900 CE). In these analyses we treated the well-established phenomenon of tit-for-tat violence as the default process, and investigated whether the climate variables had an impact on conflict beyond that attributable to the default process. Since the conflict data were derived from inscriptions on monuments, variation in the number of monuments erected and/or preserved could be a confounding factor. To address this, we included the number of monuments as a variable in all the analyses. In each analysis, we compared four models using Bayes Factors to assess their evidential support:

- Tit-for-tat-Conflict levels affected solely by tit-for-tat violence;

- Temperature-Conflict levels affected by tit-for-tat violence and summer temperature;

- Rainfall—Conflict levels affected by tit-for-tat violence and rainfall; and,

- Combined—Conflict levels affected by tit-for-tat violence, rainfall, and summer temperature.

Because Bayes Factors are relative measures of evidential strength, we adopted Jeffrey's [27] framework for interpreting our results. According to this framework, Bayes Factor differences much lower than one indicate support for the baseline model, Tit-for-Tat. Bayes Factors close to one indicate that we cannot distinguish between a given model 
Table 1: Model results. The table below is divided into three sections, each corresponding to one of the time periods analyzed (indicated in the first column). Within each section, the rows represent the primary results of a single model. The second column indicates which if any climate covariates were included in a given model: "Tit-for-Tat" indicates a tit-for-tat only model; "Temperature" a model containing the temperature covariate; and so on. The third column contains the Bayes Factors, which indicate the weight of evidence for each model in a given time period relative to the baseline, Tit-for-Tat model. The Bayes Factors can be straightforwardly interpreted as the number of times more probable a given model is than the Tit-for-Tat model. Note that because the Bayes Factors are time-period specific, they cannot be compared between time periods. The last two columns contain the mean of the posterior density of the regression coefficient estimated for a given climate covariate.

\begin{tabular}{|c|c|c|c|c|}
\hline Timespan & Model & $\begin{array}{l}\text { Bayes } \\
\text { Factor }\end{array}$ & $\begin{array}{l}\text { Temp. } \\
\text { Coef. }\end{array}$ & $\begin{array}{l}\text { Rain. } \\
\text { Coef. }\end{array}$ \\
\hline \multirow{4}{*}{$\begin{array}{l}\text { Classic } \\
(292-900 \mathrm{CE})\end{array}$} & Tit-for-tat & 1 & & \\
\hline & Temperature & 0 & 0.74 & \\
\hline & Rainfall & 0.07 & & -0.36 \\
\hline & Combined & 0.15 & 0.62 & -0.27 \\
\hline \multirow{4}{*}{$\begin{array}{l}\text { Early Classic } \\
(292-600 \mathrm{CE})\end{array}$} & Tit-for-tat & 1 & & \\
\hline & Temperature & 0.46 & 1.97 & \\
\hline & Rainfall & 0 & & 2.48 \\
\hline & Combined & 0.44 & 2.1 & 2.17 \\
\hline \multirow{4}{*}{$\begin{array}{l}\text { Late Classic } \\
(600-900 \mathrm{CE})\end{array}$} & Tit-for-tat & 1 & & \\
\hline & Temperature & 3.11 & 0.49 & \\
\hline & Rainfall & 0.87 & & -0.86 \\
\hline & Combined & 16.74 & 0.33 & -0.88 \\
\hline
\end{tabular}

and Tit-for-Tat; factors between one and five indicate weak evidence favouring a given model over Tit-for-Tat; factors between ten and fifteen indicate substantial evidence; and factors greater than fifteen indicate strong evidence.

\section{Results}

The conflict count time-series for the entire Classic period (292-900 CE) indicates there was a substantial increase in conflict between the Early and Late periods (Fig. 2). That this pattern is real and not simply an artifact of the epigraphic record is supported by several other lines of evidence, including defensive architecture, settlement placement, weaponry, and skeletal remains [48, 26, 9, 47, 11, 36].

In the analysis that dealt with the Classic period as a whole, there was at least substantial evidence that Tit-for-tat outperformed the other models (Table 1). This indicates that over the full span of the data there is no consistent relationship between conflict levels and temperature, rainfall, or the two climate variables combined. Instead, the variation in conflict counts is best explained by tit-for-tat violence alone.

The results for the analysis that focused on the Early Classic period are similar, though less decisive (Table 1). Again, none of the models containing climate covariates outperformed Tit-for-tat, but the evidence in favour of Tit-for-Tat over the other models is weak.

The situation with respect to the Late Classic is decidedly different. The results of the analysis pertaining to this period indicate that the model containing both temperature and rainfall as covariates, Combined, not only outperformed the other two climate models but also substantially outperformed Tit-for-tat (Table 11). According to Jeffrey's [27] framework, there is strong evidence favouring Combined over Tit-for-Tat. The posterior densities of the regression coefficients of Combined indicate a $62 \%$ chance that temperature increases led to increased conflict, while there is an $87 \%$ chance that reductions in rainfall reduced conflict (Figure 3). Thus, for the Late Classic, it seems that both temperature and rainfall affected conflict levels, but the impact of the latter variable was the reverse of that suggested by the Kennett et al. [28] analysis, i.e. increased aridity led to decreases in conflict rather than increases.

\section{Discussion and Conclusions}

The analyses reported here agree with the prior work of Kennett et al. [28] and Carleton et al. [7] in suggesting that climate change affected Classic Maya conflict, but the specifics of that impact differ. This suggests that data resolution was indeed at least partly responsible for the disagreement between the two studies. 


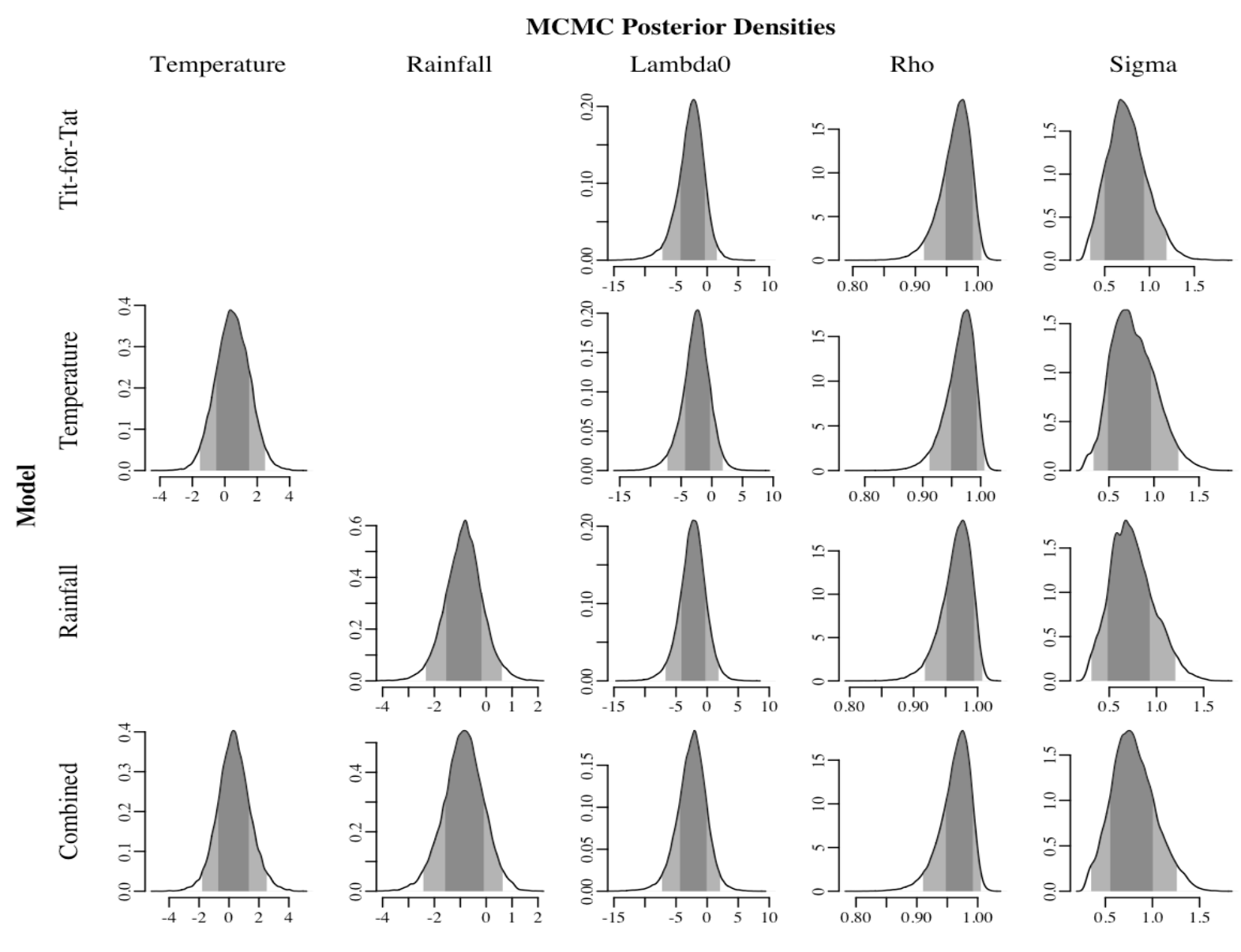

Figure 3: Posterior densities for the main parameters of each of the four models for the period 600-900 CE. Each row shows the results for a given model and each column the densities for a given parameter. The density functions contain two shaded regions: light grey corresponds to the $95 \%$ highest density region; and the dark grey corresponds to the $68 \%$ highest density region.

One important difference between our findings and those of Kennett et al. [28] and Carleton et al. [7] is the length of time over which climate change affected conflict. Kennett et al. [28] and Carleton et al. [7] found that climate change affected conflict levels over the whole of the Classic period. In contrast, our analyses indicate that climate change had no clear effect on conflict in the Early Classic but did have a significant impact in the Late Classic.

That we identified a climate-conflict relationship only in the Late Classic can be explained relatively easily, we think. The crux of the matter is the marked increase in conflict that occurred towards the end of the Early Classic (Fig. 2). We suspect that prior to this increase conflict levels were simply not variable enough for us to discern a correlation between conflict and climate change, whereas after the increase in conflict levels the variation was sufficiently large for the impact of the climate variables to be seen. Importantly, the analysis of the whole Classic period indicates that the increase in conflict is not attributable to climate change. To reiterate, in the analysis in question Tit-for-tat outperformed the climate models, which means that the increase in conflict is more parsimoniously explained by an increase in tit-for-tat violence than it is by climate change. Plotting the posterior means of the random autocorrelated process used to represent tit-for-tat violence adds weight to this explanation (Fig. 4). The plot shows that the process in question was capable of producing the observed shift in conflict levels without any exogenous influences. In sum, then, we think climate variables likely affected conflict levels throughout the Classic period but their effects only became discernible after a spontaneous increase in tit-for-tat violence near the end of the Early Classic.

The other substantive difference between our results and those of Kennett et al. [28] and Carleton et al. [7] involves the way in which climate change affected conflict. To reiterate, Kennett et al. [28] concluded that increased aridity caused increases in conflict, while Carleton et al. [7] found that increases in temperature led to more conflict. In contrast, our analyses suggest that both rainfall and temperature affected conflict. Specifically, they suggest that during the Late 


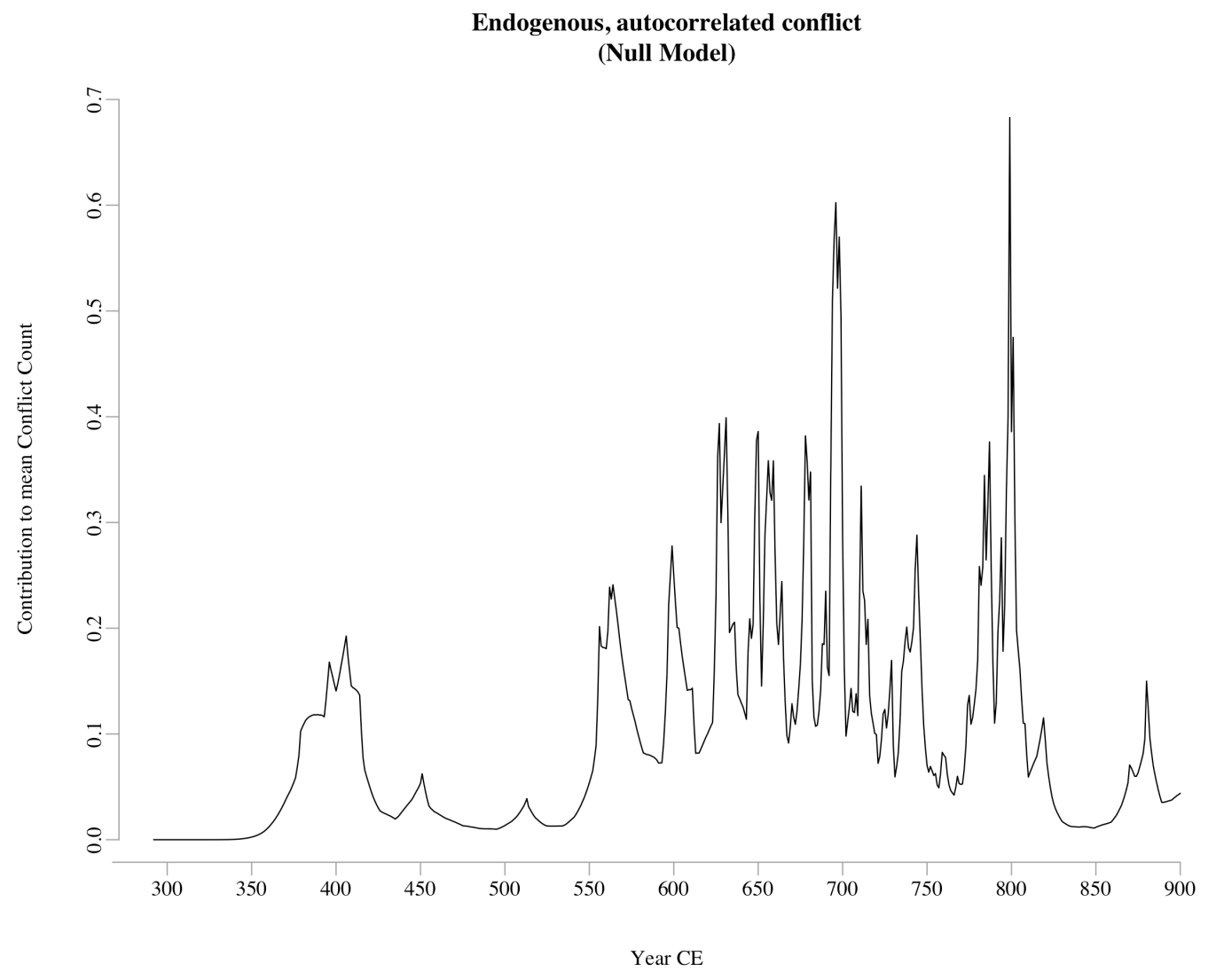

Figure 4: Posterior means of the endogenous, autocorrelated process in the tit-for-tat model (292-900 CE). In our models involving climate covariates, the effects of climate change are added to this variable to estimate the level of conflict observed in the record. In the tit-for-tat models, though, no covariates are included, which means this process drives the variation in conflict for those models. The time-series here shows that an autocorrelated process (with no covariates) can plausibly account for some of the sudden increase in conflict numbers between the Early and Late Classic. In fact, our analyses show that the tit-for-tat model for the whole Classic period-which contains only this random, autocorrelated process - accounts for the increase better than any of the models involving climate covariates.

Classic, higher summer temperatures resulted in higher conflict levels than would have been expected under cooler conditions, while increased dryness reduced conflict levels compared to what would have been expected under wetter conditions. Significantly, adding an interaction between the two climate variables did not improve the best model (Table S2). Thus, the effects of summer temperature and rainfall on conflict levels are independent of one another.

Our finding that higher summer temperatures exacerbated conflict is consistent with the hypothesis developed by Carleton et al. [7] to explain their results. The hypothesis argues that this relationship was mediated the interaction between temperature and the productivity of the Classic Maya's staple crop, maize. Temperature has a non-linear impact on maize yields. Yields increase as temperature increases but only to 30C. Above that temperature, they decline precipitously. Carleton et al. [7] argued that their data were consistent with an increasing number of growing season days above $30 \mathrm{C}$ and consequently an increasing number of years with maize harvest shortfalls. These shortfalls, they suggested, would have precipitated crises of legitimacy for rulers because political authority was tied to maize productivity. In order to cope with this situation, Carleton et al. [7] proposed, members of the elite organized attacks on other polities, hoping that victory would restore that lost legitimacy.

Salehyan and Hendrix [39] outlined a hypothesis that may explain why we found that increasing aridity reduced conflict in the Late Classic. These authors proposed that water scarcity has a pacifying effect. They suggested that people will only engage in political violence if they can get enough to eat and drink and accomplishing the latter is harder when water is in short supply. Consequently, periods of drought can be expected to be associated with lower levels of political violence. Salehyan and Hendrix [39] tested this hypothesis with conflict data from 165 modern societies and obtained 
results that they argued strongly supported it. While the specifics of Salehyan and Hendrix's [39] proposal require investigation, it seems like a plausible explanation for the association between increased aridity and decreased conflict that we identified. Strikingly, the Maya region has few sources of freshwater and therefore the ability of the Classic Maya to meet their basic material needs likely would have been particularly susceptible to below-average precipitation [29, 30].

The present study has implications beyond the debate about the impact of climate change on Classic Maya conflict. One concerns the impact of drought on the Maya. Researchers have long viewed drought as a paramount environmental factor in the history of the Maya [e.g., 35, 40]. It has featured prominently in discussions of Maya ecology [e.g., 25, 45, 42, 30, 31, 10] and has been posited as a causal factor in several social, political, and economic upheavals, including the collapse of the Classic Maya civilization [e.g., 45, 20, 15, 16, 13, 29, 22, 10]. However, our findings suggest that the importance of drought may have been overestimated. They imply, for example, that where violence was involved in a particular historical event, temperature increase may have been an important causal factor. Given this, it would be worthwhile reexamining the evidence for events and trends in Maya history currently thought to have been driven by drought in order to assess whether temperature and other environmental variables might have been responsible.

Our results have another implication for current thinking about one of the most important upheavals, the collapse of Classic Maya civilization. The collapse, which began around $900 \mathrm{CE}$ and lasted for about 200 years, was a complicated, spatially variable process that involved severe economic deterioration, the dissolution of the system of divine kingship, and the abandonment of many major centres [8, 12, 13, 2]. Numerous researchers have argued that drought drove these changes by destabilizing the agroeconomic basis of the divine kingship system [e.g., 29, 16, 22, 10]. However, it has also been proposed that increasing conflict caused, or at least contributed to, the collapse [18, 12, 10, 45]. Our results indicate that these hypotheses are unlikely to both be true. The reason for this is that they imply that aridity and conflict should be positively correlated in the Late Classic, which is the opposite of what we found. One of the hypotheses may be correct, but not both.

Lastly, while our finding that heat and aridity had opposite effects is unexpected in the context of previous work on Classic Maya conflict, it is in line with the results of some of the studies that have investigated the impact of climate change on conflict in modern societies. Several of these studies have concluded that increasing temperature exacerbates conflict [e.g., 24] and a number of others have found that increased aridity suppresses it [e.g., 39, 49]. A few studies have even reported finding that conflict levels in their region of interest are increased by higher temperatures and decreased by greater aridity. Burke et al. [6], for instance, determined that warmer temperatures elevated the risk of civil war in sub-Saharan Africa between 1981 and 2002 whereas increased aridity suppressed it. The same pattern was observed in a recent study of political violence in Kenya between 1989 and 2004 [43]. This convergence of results is particularly intriguing given that the Classic Maya and modern societies are not only separated by over 1,000 years but also have marked socioeconomic differences. It raises the possibility that we are looking at a general phenomenon.

\section{Materials and Methods}

The dataset used in the study consists of annual values for the period 292-900 CE for four variables. The first is the number of inter-polity conflicts per year. Values for this variable were obtained from several sources (Supplementary Information). The second variable is the number of monuments erected each year. We included this variable because the conflict counts derive from inscriptions on stelae and other monuments and we wanted to control for the impact of simple variation in the number of monuments erected. These data were collected from the same sources as the conflict data. The third variable is an oxygen isotope $\left(\delta^{18} O\right)$ record from Yok Balum Cave, Belize, that reflects variation in rainfall [28]. The original $\delta^{18} O$ record has a subannual resolution, so we created an annual record by calculating average values at one-year intervals. The last variable is a summer sea-surface temperature (SST) reconstruction based on $\mathrm{Mg} / \mathrm{Ca}$ ratios of foraminifera contained in a sediment core from the Cariaco Basin [50].

To determine which, if either, of the climate variables best explains the variation in conflict counts we created a new, Bayesian model for analysing count-based time-series. Carleton et al. [7] used the Poisson Exponentially-Weighted Moving Average (PEWMA) model [3] to assess the impact of climate change on Classic Maya conflict. However, we could not employ the PEWMA model in the present study because it cannot cope with long strings of zeros and there are several periods in our annually-resolved dataset, particularly in the Early Classic, when relatively few conflicts are mentioned.

The model we developed is a flexible Bayesian state-space time-series model (see Fig. 5 for a schematic). State-space models are used to differentiate between observations and the process that produced them. The process is considered latent-i.e., it cannot be directly observed, and its parameters must instead be estimated based on a given set of observations. A state-space models are defined by a set of equations. One equation represents the dependent variables 
that are actually observed, while another represents the unobserved latent process, which is affected by the independent covariates.

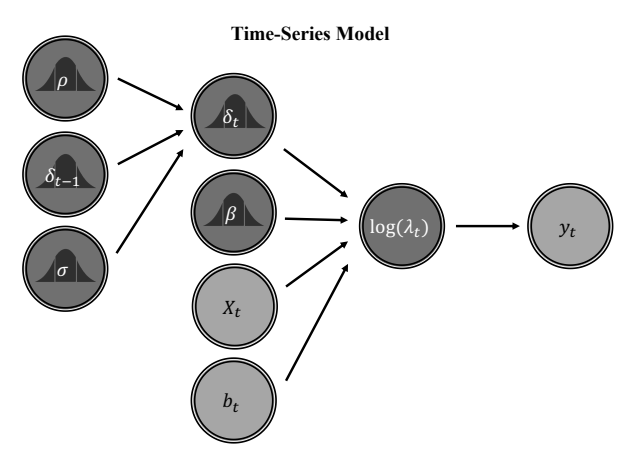

Figure 5: Directed acyclic graph for the time-series model. In this image, Light grey circles represent data- $y_{t}$ refers to conflicts dated to a given time; $X_{t}$ refers to a matrix of covariates; and $b_{t}$ is the number of monuments dated to a given time. Dark grey circles represent terms estimated from the data (see 17 ). The dark grey density symbols indicate probabilistic terms, and terms without subscripts are non-time varying.

To analyse our Classic Maya conflict record, we assumed that the observed conflict time-series was produced by an unobservable conflict-generating process. Since the observed conflict time-series is count-based, and there is no such thing as fractional or negative conflict, an appropriate basis for the model is the Poisson distribution. Thus, the number of conflicts per period can be thought of as a series of Poisson-distributed random variables, denoted $Y=\left[y_{1}, y_{2} \ldots, y_{t}\right]$ where $t$ is the number of periods. The conflict-count variables are therefore modelled as follows:

$$
y_{t} \sim P\left(\lambda_{t}\right)
$$

In this equation, $y_{t}$ is the number of conflicts at time $t$, and $\lambda_{t}$ is the mean of the Poisson-distributed process. The mean of the conflict-count process is, in turn, determined by the latent, unobservable, conflict process, which includes external inputs in the form of covariates. This latent process is represented by the following equation:

$$
\lambda_{t}=b_{t} e^{X_{t} \beta+\delta_{t}}
$$

In Equation 2, $b_{t}$ is the number of monuments dated to time $t$. This term was included to control for the potentially confounding effects of variation in the number of monuments erected per year. It also implies the model can be interpreted as estimating the average number of conflicts per monument. The next two terms are a matrix of (meancentered) covariates, $X_{t}$, and a vector of regression coefficients, $\beta$, both related to the Poisson mean by a log-link function, which is why they are exponents of $e$. The last term, $\delta_{t}$, is also an exponent of $e$ and it represents the underlying, endogenous autocorrelated conflict process. By including this term, we accounted for the observable autocorrelation in the conflict record (Fig. S1), which seems likely to be due, at least in part, to cycles of retribution. To model these dynamics, we used an autocorrelated normally-distributed process,

$$
\delta_{t} \sim N\left(\rho \delta_{t-1}, \sigma\right)
$$

where the mean is represented by $\rho \delta_{t-1}$ and the standard deviation is represented by $\sigma$. The mean, $\rho \delta_{t-1}$ has two parts. The first, $\rho$, is an autocorrelation term; the second, $\delta_{t-1}$, is the level of the endogenous conflict process at the previous time (i.e., t-1). The autocorrelation term applies a weight to the influence of past conflict counts on present and future conflict. A positive value for $\rho$ implies that endogenous conflict is increasing over time because the influence of past conflict is accumulating whereas a negative value implies it is declining because the influence is diminishing. The standard deviation of the distribution, $\sigma$, determines the volatility of the endogenous autocorrelated conflict process. Higher $\sigma$ indicates higher magnitude fluctuations in the endogenous conflict process while lower $\sigma$ indicates lower magnitude fluctuations.

Because the model is Bayesian, several parameters have prior distributions. The priors we used all have large variances because we were agnostic about their true values. The priors include normal distributions for the regression coefficients 
( $\beta$ ) of Eq. 2, the autocorrelation coefficient $(\rho)$ of Eq. 3 and the first estimate of the endogenous conflict process $\left(\delta_{0}\right)$ in Eq. 3. The last of these is the estimated level of conflict in the period immediately prior to the beginning of the conflict record. These three priors were parameterized as follows:

$$
\begin{aligned}
\beta & \sim N(0,1000) \\
\rho & \sim N(0,1000) \\
\delta_{0} & \sim N(0,1000)
\end{aligned}
$$

We also used a prior for the standard deviation, $\sigma$, in Equation 3. Instead of a normal distribution, however, we used an exponential one so that the value would be positive, which is a requirement for standard deviations. This prior was parameterized as follows:

$$
\sigma \sim \operatorname{Exp}(0.1)
$$

All of the prior distributions were ultimately transformed by the data and likelihood for the model via Bayes Theorem into posterior estimates of the relevant parameters [14].

We carried out three analyses with the Bayesian model. In the first, we examined the impact of rainfall and temperature on conflict across the whole time period covered by our dataset (292-900 CE). In the second, we re-ran the analysis but only included data from the Early Classic period (292-600 CE). In the third and final analysis, we once again examined the impact of rainfall and temperature on conflict but this time we focused on data from the Late Classic period (600-900 $\mathrm{CE})$. We carried out these analyses because it is thought that socio-political conditions changed significantly between the Early Classic and Late Classic periods [42, 10] and it seemed possible that the change could have been relevant to the climate-conflict relationship.

In each analysis, we compared four models, each of which accounted for changes in monument numbers. The first was a "Tit-for-Tat" only model-i.e., eq. 2 with the regression term, $X_{t} \beta$, removed. It included no covariates, only the conflict data. The interpretation of this model is that conflict counts are only determined by past conflict and not by climate change. The next two models included a climate time-series as a covariate. One included the $\delta^{18} O$ rainfall record, while the other included the summer SST record. These models imply that conflict counts are the product of past conflict and the relevant climate variable. The fourth and final model included both of the temperature and rainfall variables as covariates. According to this model, conflict counts are a product of past (endogenous) conflict and temperature and rainfall.

To compare the models for a given time-period, we used Bayes Factors [14]. The Bayes Factors indicate the weight of evidence for a model given the data relative to the baseline "Tit-for-Tat" model from the same period-higher Bayes Factors indicate better fitting models. Importantly, they cannot be used for comparing models from different time-periods. We reasoned that in order for a given climate covariate to be considered important for explaining variation in Classic Maya conflict in a given analysis (time-period), the model containing it had to have a higher Bayes Factor than the other models in that analysis and a higher Bayes Factor than the "Tit-for-Tat" only model.

To estimate the posterior distributions of the parameters for each model and the posterior probabilities for the models themselves, we used a Markov-Chain Monte Carlo (MCMC) approach. Each MCMC simulation was run for 200,000 iterations the first 100,000 of which were discarded as burn-in. The calculations were performed in R [34] with the help of a newly developed Bayesian model estimation package called "Nimble" [33]. The code used in the study can be found on GitHub (https://github.com/wccarleton/conflict).

\section{References}

[1] W. N. Adger, J. M. Pulhin, J. Barnett, G. D. Dabelko, G. K. Hovelsrud, M. Levy, Ú. O. Spring, and C. H. Vogel. Human Security. In C. Field, V. Barros, D. Dokken, K. Mach, M. Mastrandrea, T. Bilir, M. Chatterjee, K. Ebi, Y. Estrada, R. Genova, B. Girma, E. Kissel, A. Levy, S. MacCracken, P. Mastrandrea, and L. White, editors, Climate change 2014 : impacts, adaptation, and vulnerability : Working Group II contribution to the fifth assessment report of the Intergovernmental Panel on Climate Change, pages 755-791. Cambridge University Press, Cambridge, UK, 2014.

[2] J. J. Aimers. What Maya collapse? Terminal classic variation in the Maya lowlands. Journal of Archaeological Research, 15(4):329-377, 2007. 
[3] P. T. Brandt, J. T. Williams, B. O. Fordham, and B. Pollins. Dynamic modeling for persistent even count time series. American Journal of Political Science, 44(4):823-843, dec 2000.

[4] M. K. Brown and T. W. Stanton. Ancient Mesoamerican warfare. AltaMira Press, Walnut Creek, 2003.

[5] H. Buhaug. Climate not to blame for African civil wars. Proceedings of the National Academy of Sciences of the United States of America, 107(38):16477-82, sep 2010.

[6] M. B. Burke, E. Miguel, S. Satyanath, J. A. Dykema, and D. B. Lobell. Warming increases the risk of civil war in Africa. Proceedings of the National Academy of Sciences of the United States of America, 106(49):20670-20674, feb 2009.

[7] W. C. Carleton, D. Campbell, and M. Collard. Increasing temperature exacerbated Classic Maya conflict over the long term. Quaternary Science Reviews, 163:209-218, may 2017.

[8] T. P. Culbert. The Classic Maya Collapse. University of New Mexico Press, Albuquerque, first edit edition, 1973.

[9] B. H. Dahlin. The Barricade and Abandonment of Chunchucmil : Implications for Northern Maya Warfare. Latin American Antiquity, 11(3):283-298, jun 2000.

[10] A. A. Demarest. Ancient Maya : the rise and fall of a rainforest civilization. Cambridge University Press, Cambridge, 2004.

[11] A. a. Demarest, M. O’Mansky, C. Wolley, D. Van Tuerenhout, T. Inomata, J. Palka, and H. Escobedo. Classic Maya Defensive Systems and Warfare in the Petexbatun Region: Archaeological Evidence and Interpretations. Ancient Mesoamerica, 8(02):229-253, jun 1997.

[12] A. A. Demarest, P. M. Rice, and D. S. Rice. The Terminal Classic in the Maya Lowlands: Assessing Collapses, Terminations, and Transformations. University Press of Colorado, 2004.

[13] N. P. Dunning, T. P. Beach, and S. Luzzadder-Beach. Kax and kol: collapse and resilience in lowland Maya civilization. Proceedings of the National Academy of Sciences of the United States of America, 109(10):3652-7, nov 2012.

[14] A. Gelman, J. B. Carlin, H. S. Stern, D. B. Dunson, A. Vehtari, and D. B. Rubin. Bayesian Data Analysis. CRC Press, Boca Raton, 3rd edition, 2014.

[15] R. B. Gill. The Great Maya Droughts: Water, Life, and Death. University of New Mexico Press, 2000.

[16] R. B. Gill, P. A. Mayewski, J. Nyberg, G. H. Haug, and L. C. Peterson. Drought and the Maya Collapse. Ancient Mesoamerica, 18(02), 2007.

[17] N. P. Gleditsch. Whither the weather? Climate change and conflict. Journal of Peace Research, 49(1):3-9, jan 2012.

[18] R. L. Hamblin and B. L. Pitcher. The Classic Maya Collapse: Testing Class Conflict Hypotheses. American Antiquity, 45(2):246-267, jul 1980.

[19] R. Hassig. War and Society in Ancient MesoAmerica. University of California Press, Berkeley, 1992.

[20] G. H. Haug, D. Günther, L. C. Peterson, D. M. Sigman, K. A. Hughen, and B. Aeschlimann. Climate and the collapse of Maya civilization. Science, 299(5613):1731-5, mar 2003.

[21] High Representative of the European Union for Foreign Affairs and Security Policy. Joint communication to the European Parliament and the Council: The EU's Comprehensive Approach to External Conflict and Crises, 2013.

[22] D. A. Hodell, M. Brenner, and J. H. Curtis. Terminal Classic drought in the northern Maya lowlands inferred from multiple sediment cores in Lake Chichancanab (Mexico). Quaternary Science Reviews, 24(12-13):1413-1427, jul 2005.

[23] S. D. Houston, O. F. Chinchilla Mazariegos, and D. Stuart. The decipherment of ancient Maya writing. University of Oklahoma Press, Norman, 2001.

[24] S. M. Hsiang, M. Burke, and E. Miguel. Quantifying the influence of climate on human conflict. Science, 341(6151):1235367, aug 2013.

[25] G. Iannone, J. Yaeger, and D. A. Hodell. The Great Maya Droughts: A Critical Introduction. In Great maya droughts in cultural context: case studies in resilience and. University Press Of Colorado, Boulder, Colorado, 2013.

[26] T. Inomata and D. Triadan. Culture and Practice of War in Maya Society. In A. E. Nielsen and W. H. Walker, editors, Warfare in Cultural Context: Practice, Agency, and The Archaeology of Violence, pages 56-83. University of Arizona Press, Tuscon, 2009.

[27] H. Jeffreys. Theory of probability. Clarendon Press, Oxford, third edit edition, 1998. 
[28] D. J. Kennett, S. F. Breitenbach, V. V. Aquino, Y. Asmerom, J. Awe, J. U. Baldini, P. J. Bartlein, B. J. Culleton, C. Ebert, C. Jazwa, M. J. Macri, N. Marwan, V. Polyak, K. M. Prufer, H. E. Ridley, H. Sodemann, B. Winterhalder, and G. H. Haug. Development and disintegration of maya political systems in response to climate change. Science, 338(6108):788-791, may 2012.

[29] L. J. Lucero. The Collapse of the Classic Maya: A Case for the Role of Water Control. American Anthropologist, 104(3):814-826, nov 2002.

[30] L. J. Lucero, J. D. Gunn, and V. L. Scarborough. Climate Change and Classic Maya Water Management. Water, 3(2):479-494, nov 2011.

[31] S. Luzzadder-Beach, T. Beach, S. Hutson, and S. Krause. Sky-earth, lake-sea: climate and water in Maya history and landscape. Antiquity, 90(350):426-442, aug 2016.

[32] S. Martin and N. Grube. Chronicle of the Maya kings and queens : deciphering the dynasties of the ancient Maya. Thames \& Hudson, London, revised ed edition, 2008.

[33] NIMBLE Development Team. Nimble user manual, 2018. R package manual version 0.6-12.

[34] R Core Team. R: A Language and Environment for Statistical Computing, 2019.

[35] W. L. Rathje. The Origin and Development of Lowland Classic Maya Civilization. American Antiquity, 36(03):275285, jul 1971.

[36] D. S. Rice and P. M. Rice. Muralla de Leon: a Lowland Maya Fortification. Journal of Field Archaeology, 8(3):271-288, jun 1981.

[37] P. M. Rice. Time, Power, and the Maya. Latin American Antiquity, 19(3):275-298, nov 2008.

[38] I. Salehyan. Climate change and conflict: Making sense of disparate findings. Political Geography, 43:1-5, nov 2014.

[39] I. Salehyan and C. S. Hendrix. Climate shocks and political violence. Global Environmental Change, 28:239-250, sep 2014.

[40] V. L. Scarborough. Ecology and Ritual: Water Management and the Maya. Latin American Antiquity, 9(02):135159, jun 1998.

[41] J. Scheffran, M. Brzoska, J. Kominek, P. M. Link, and J. Schilling. Disentangling the Climate-conflict Nexus: Empirical and Theoretical Assessment of Vulnerabilities and Pathways. Review of European Studies, 4(5):1-13, sep 2012.

[42] R. J. Sharer and L. P. Traxler. The ancient Maya. Stanford University Press, Stanford, Calif., 6th edition, 2006.

[43] O. M. Theisen. Climate clashes? Weather variability, land pressure, and organized violence in Kenya, 1989-2004. Journal of Peace Research, 49(1):81-96, jul 2012.

[44] R. S. J. Tol and S. Wagner. Climate change and violent conflict in Europe over the last millennium. Climatic Change, 99(1):65-79, jul 2010.

[45] B. L. Turner and J. a. Sabloff. Classic Period collapse of the Central Maya Lowlands: insights about humanenvironment relationships for sustainability. Proceedings of the National Academy of Sciences, 109(35):13908-14, 2012.

[46] U.S. Department of Defense. Quadrennial Defense Review Report 2010, 2010.

[47] D. L. Webster. Three walled sites of the northern Maya lowlands. Journal of Field Archaeology, 5(4):375-390, sep 1978.

[48] D. L. Webster. The not so peaceful civilization: A review of Maya war. Journal of World Prehistory, 14(1):65-119, jan 2000.

[49] K. M. Witsenburg and W. R. Adano. Of Rain and Raids: Violent Livestock Raiding in Northern Kenya. Civil Wars, 11(4):514-538, dec 2009.

[50] J. B. Wurtzel, D. E. Black, R. C. Thunell, L. C. Peterson, E. J. Tappa, and S. Rahman. Mechanisms of southern Caribbean SST variability over the last two millennia. Geophysical Research Letters, 40(22):5954-5958, aug 2013.

[51] Z. Zhang, H. Tian, B. Cazelles, K. L. Kausrud, A. Bräuning, F. Guo, and N. C. Stenseth. Periodic climate cooling enhanced natural disasters and wars in China during AD 10-1900. Proceedings of the Royal Society B: Biological Sciences, 277(1701):3745-53, dec 2010. 